nomson

glyndŵn

Glyndŵr University

Glyndŵr University Research Online

Advanced Materials Research Laboratory

Materials Science

$4-1-2002$

\title{
Polymer electrolytes based on modified natural rubber
}

Roger Linford

Glyndwr University, r.linford@glyndwr.ac.uk

M Glasse

R Idris

R Latham

Follow this and additional works at: http:/ / epubs.glyndwr.ac.uk/amrl

Part of the Materials Science and Engineering Commons

\section{Recommended Citation}

Glasse, M.D., Idris, R., Latham, R.J., Linford, R.G., \& Schlindwein, W.S. (2002) 'Polymer electrolytes based on modified natural rubber.'Solid State Ionics, 147(3-4), 289-294

This Article is brought to you for free and open access by the Materials Science at Glyndwir University Research Online. It has been accepted for inclusion in Advanced Materials Research Laboratory by an authorized administrator of Glyndŵr University Research Online. For more information, please contact d.jepson@glyndwr.ac.uk. 


\title{
Polymer electrolytes based on modified natural rubber
}

\begin{abstract}
Modified natural rubber polymer hosts having low transition glass temperatures have been investigated for use in polymer electrolytes. Two types of modified natural rubber, namely $25 \%$ epoxidised natural rubber (ENR-25) and 50\% epoxidised natural rubber (ENR-50) were employed in conjunction with poly(ethylene oxide), PEO. Results are reported for ionic conductivity and thermal properties for both unplasticized and plasticized polymer electrolyte systems with lithium triflate. The samples were in the form of free standing films with the thickness $0.2-0.5 \mathrm{~mm}$ and mixtures of ethylene carbonate (EC) and propylene carbonate (PC) were used as plasticizers. Unplasticized modified natural rubber-based systems exhibit ionic conductivities in the range 10-6 to $10-5 \mathrm{~S} \mathrm{~cm}-1$ at ambient temperatures. Incorporating $100 \%$ of EC/PC by weight fraction of polymer (ENR/PEO) to the systems yielded mechanically stable films and ionic conductivities in the range of $10-4 \mathrm{~S} \mathrm{~cm}-1$ at ambient temperature.
\end{abstract}

\section{Keywords}

Ionic conductivities, Batteries, polymer electrolytes, natural rubber

\section{Disciplines}

Materials Science and Engineering

\section{Comments}

Link to published version of this article http: //www.sciencedirect.com Copyright (C) 2002 Elsevier Science B.V. 


\title{
Polymer electrolytes based on modified natural rubber
}

\author{
M D Glasse, R Idris ${ }^{1}$, R J Latham, R G Linford and W S Schlindwein \\ Solid State Research Centre, Faculty of Applied Sciences, De Montfort University, \\ The Gateway Leicester, LE1 9BH, UK
}

\begin{abstract}
Modified natural rubber polymer hosts having low transition glass temperatures have been investigated for use in polymer electrolytes. Two types of modified natural rubber, namely $25 \%$ epoxidised natural rubber (ENR-25) and 50\% epoxidised natural rubber (ENR-50) were employed in conjunction with poly(ethylene oxide), PEO. Results are reported for ionic conductivity and thermal properties for both unplasticized and plasticized polymer electrolyte systems with lithium triflate. The samples were in the form of free standing films with the thickness $0.2-0.5 \mathrm{~mm}$ and mixtures of ethylene carbonate (EC) and propylene carbonate (PC) were used as plasticizers. Unplasticized modified natural rubber based systems exhibit ionic conductivities in the range $10^{-6}$ to $10^{-5} \mathrm{~S} \mathrm{~cm}^{-1}$ at ambient temperatures. Incorporating $100 \%$ of EC/PC by weight fraction of polymer (ENR/PEO) to the systems yielded mechanically stable films and ionic conductivities in the range of $10^{-4} \mathrm{~S} \mathrm{~cm}^{-1}$ at ambient temperature.
\end{abstract}

\section{Introduction}

Polymers are now used widely as the basis of the electrolyte electrochemical devices such as displays, sensors, electrochromic windows, supercapacitors and rechargeable batteries. In particular there has been considerable interest regarding the use of polymer gel electrolyte systems in solid polymer batteries [1-3]. These systems have shown improved ionic conductivities over previous conventional solid polymer electrolyte systems [4-5]. Enhanced room temperature conductivity has been demonstrated by several types of gel polymer electrolytes and a variety of polymer hosts have been proposed as matrices for plasticized or gel polymer electrolyte systems. Typical polymer hosts are as follows :

- thermoplastic polymer hosts such as polyacrylonitrile [6-8], poly(ethylene oxide) [9], poly(methyl methacrylate) [10,11], poly(vinylchloride) [12], polyurethane [13] and polyvinylidene fluoride [14,15]

- network polymer hosts prepared by crosslinking of acrylate or methacrylate monomers having low molecular weight [16]

- $\quad$ mixtures of the polymer hosts mentioned above [17]

The main drawback of these systems is their dimensional instability with high plasticiser concentrations, i.e. in the 'gel' state. Mechanical properties can be improved by increasing the polymer-plasticiser ratio, but this adversely affects the conductivity.

An alternative approach involves the use of fillers. For example, enhancement of ambient temperature conductivity also has been observed in the development of PEO-based nanocomposite polymer electrolytes [18] incorporating inorganic fillers such as $\mathrm{Al}_{2} \mathrm{O}_{3}$ and $\mathrm{SiO}_{2}$ although the mechanisms for promoting ion transport are not fully explained.

An alternative to the use of ceramic fillers or blends is to employ a complexing but nonblending polymer such as modified natural rubber. The modification should lead to such properties as low glass transition temperature, $\mathrm{T}_{\mathrm{g}}$, soft elastomer characteristics at room temperature and good elasticity and adhesion. For example, the fabrication of flat, thin and

\footnotetext{
${ }^{1}$ Present address : SIRIM Berhad, Malaysia
} 
flexible paper-like batteries would be facilitated by materials having good elasticity, which also give excellent contact between the electrolytic layer and an electrode in batteries. Two suitably modified natural rubbers have been considered in this study in conjunction with PEO. They are $25 \%$ and $50 \%$ epoxidised natural rubbers, ENR (figure 1). This work reports the results of ionic conductivity and thermal analysis measurements performed on non-plasticized and plasticized (using ethylene carbonate, EC, and propylene carbonate, PC) ENR/PEO based polymer electrolyte systems with lithium triflate.

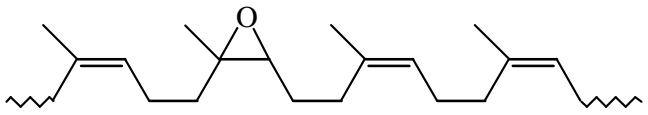

ENR-25

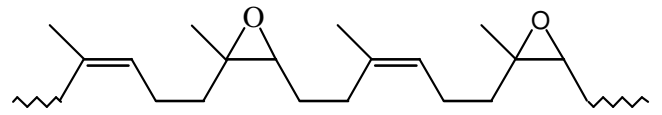

ENR-50

Figure 1 Chemical structure of the $25 \%$ and $50 \%$ epoxidised natural rubbers

\section{Experimental}

\subsection{Sample preparation}

All polymer electrolyte samples were prepared by a solvent casting method. Masticated epoxidised natural rubber supplied by the Tun Abdul Razak Rubber Research Centre, London was received as masticated sheet (passed through a two-roll mill machine about six times). The masticated ENR was cut into grain size and dissolved into tetrahydrofuran (THF) with efficient magnetic stirring. A viscous solution of ENR rubber was formed after continuous stirring overnight. Then, lithium triflate and different concentrations of PEO (RMM $4 \times 10^{6}$ ) were added to the solution. The samples ENR-25/PEO/LiCF $\mathrm{SO}_{3}, \mathrm{ENR}-50 / \mathrm{PEO} / \mathrm{LiCF} \mathrm{SO}_{3}$ ENR-25/PEO/EC:PC/LiCF $3 \mathrm{SO}_{3}$ and ENR-50/PEO/EC:PC/LiCF $3 \mathrm{SO}_{3}$ were made with lithium salt contents expressed in terms of $\mathrm{O}: \mathrm{Li}$ ratio being $5: 1,12: 1,24: 1$ and 32:1 respectively. These compositions were a consequence of maintaining a constant total mass of polymer in the electrolyte formulation. The total plasticizer concentration was based on $100 \%$ by weight of the total ENR/PEO using an EC:PC ratio of 1:1. The PEO concentration was varied from 0 to 100 weight $\%$ in the mixture with ENR. The electrolyte solutions were cast into a glass ring mould on a Teflon substrate. Free standing polymer electrolyte films of ENR/PEO, 0.2$0.5 \mathrm{~mm}$ thick, were obtained after the THF solvent had evaporated. The final films were further dried under vacuum oven for $48 \mathrm{~h}$ to remove residual solvent. Then, the films were kept in a desiccator until further use.

\subsection{Conductivity measurements}

Polymer electrolyte film samples were sandwiched between two stainless steel blocking electrodes and mounted in the test cell. A Solartron 1250 Frequency Response Analyser and 1286 Electrochemical Interface were used to measure the impedance of electrolyte films over the frequency range $0.1 \mathrm{~Hz}$ to $65 \mathrm{kHz}$. The ionic conductivity was calculated from the bulk electrolyte resistance value $\left(\mathrm{R}_{\mathrm{b}}\right)$. 


\subsection{Differential Scanning Calorimetry}

Differential Scanning Calorimetry (Perkin-Elmer DSC4 system) was employed for thermal characterization of the polymer electrolytes over a temperature range of $-80{ }^{\circ} \mathrm{C}$ to $+120{ }^{\circ} \mathrm{C}$ in a nitrogen atmosphere. Samples were rapidly cooled to $-80{ }^{\circ} \mathrm{C}$ and heated to $120{ }^{\circ} \mathrm{C}$ at a scan rate of $10{ }^{\circ} \mathrm{C} \min ^{-1}$.

\section{Results and Discussion}

\subsection{Ionic conductivity}

Typical impedance plots are shown in Figure 2. It is possible to achieve ionic conductivities for ENR-25/PEO/ $\mathrm{LiCF}_{3} \mathrm{SO}_{3}$ in the range $10^{-6}$ to $10^{-4} \mathrm{~S} \mathrm{~cm}^{-1}$. At room temperature the ionic conductivity is $1.5 \times 10^{-5} \mathrm{~S} \mathrm{~cm}^{-1}$ when the PEO concentration is $0 \%$ and is $1.3 \times 10^{-5} \mathrm{~S} \mathrm{~cm}^{-1}$ at 75 weight $\%$ of $\mathrm{PEO}$ for the same salt concentration (figure 3 ).

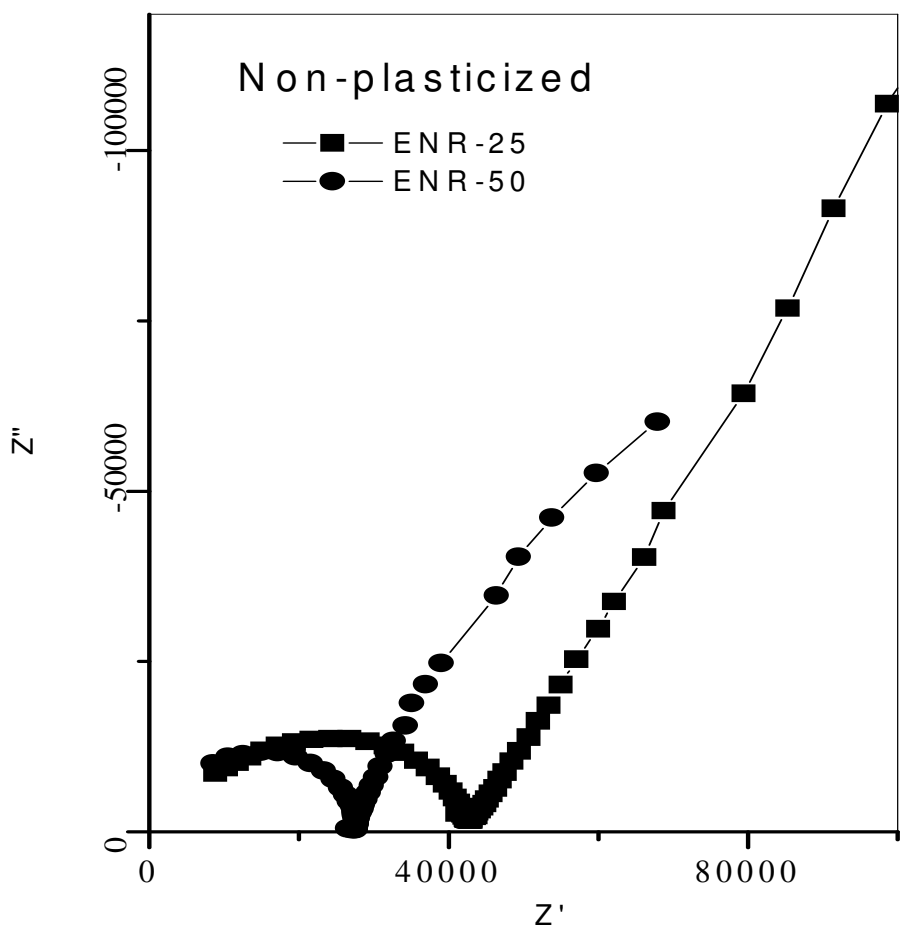

(a)

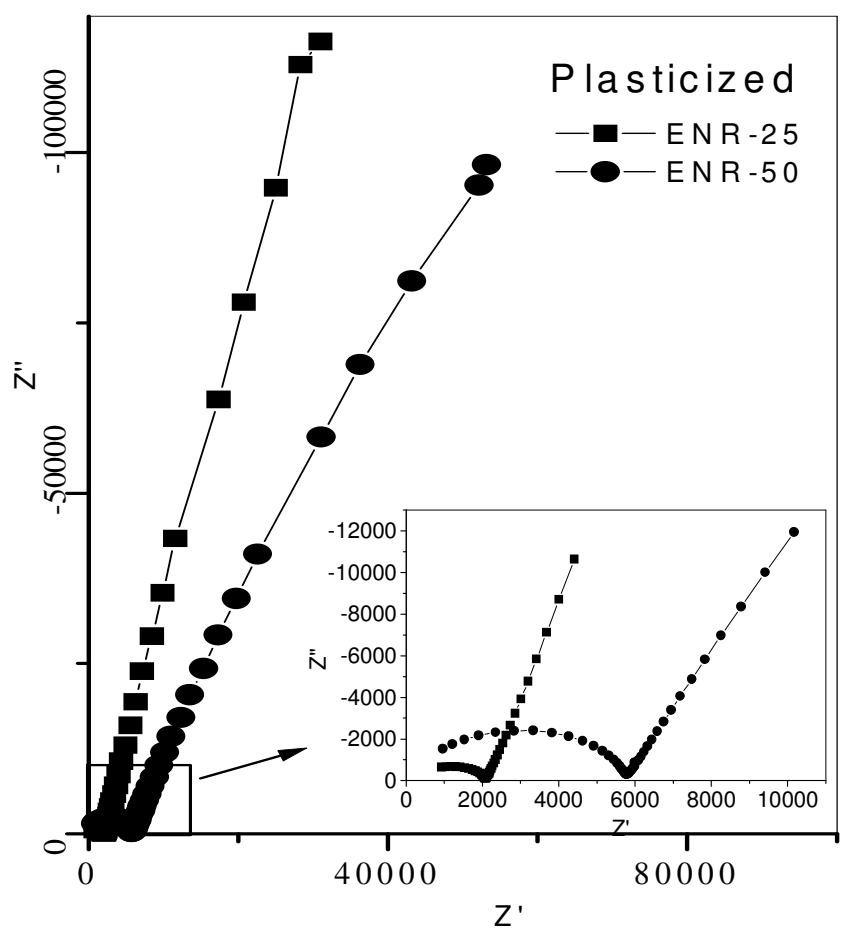

(b)

Figure 2 Impedance plots of (a) salt-doped modified natural rubber/PEO based electrolytes; (b) plasticised (EC:PC) modified natural rubber/PEO based gel electrolytes. 


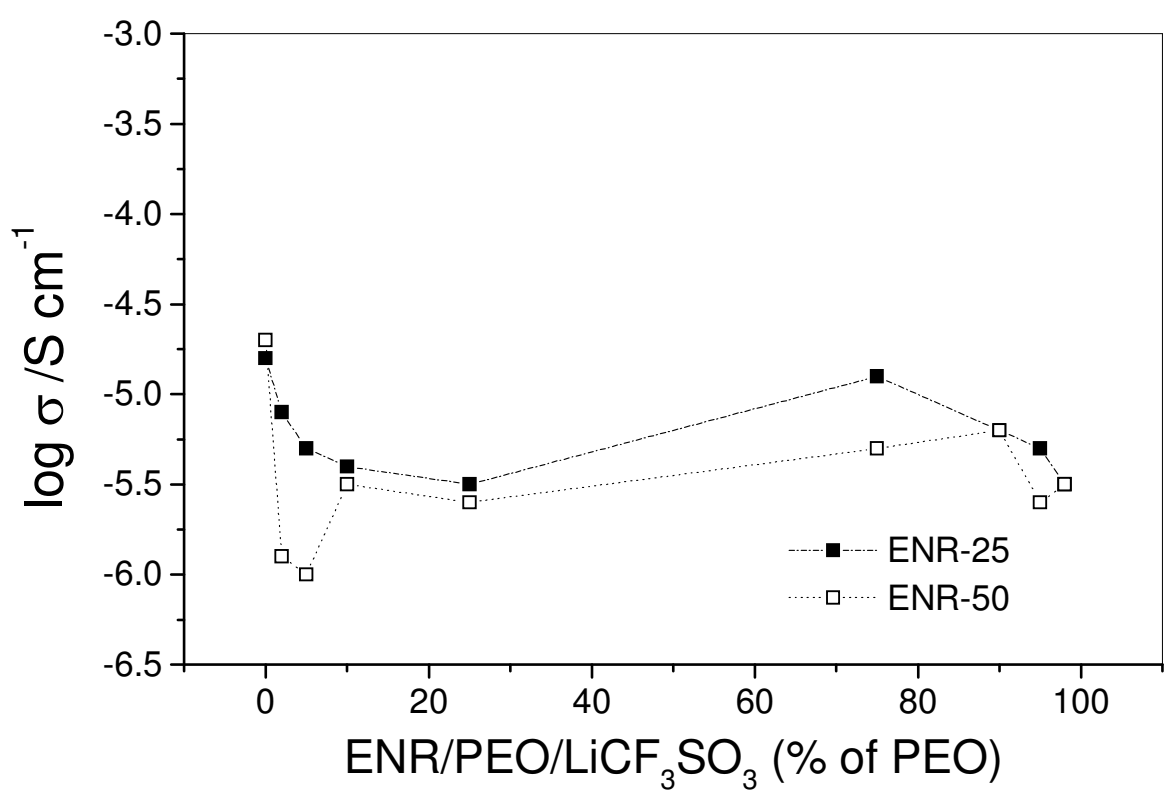

Figure 3 Conductivity as a function of $\mathrm{PEO}$ concentration of $\mathrm{ENR} / \mathrm{PEO} / \mathrm{LiCF} \mathrm{SO}_{3}$ electrolytes at room temperature.

It was observed that as the weight $\%$ PEO increases, the conductivity decreases to a minimum of $3.2 \times 10^{-6} \mathrm{~S} \mathrm{~cm}^{-1}$ and starts increasing again to a maximum when the PEO content is 75 weight \%. This behaviour was also found in the case of ENR-50/PEO based electrolytes. The reason for this particular conductivity behaviour is not fully understood at this present time. Of the modified natural rubbers, ENR-25/PEO shows the highest conductivity at room temperature for any given PEO concentration compared with the ENR-50 based electrolytes. Overall, the conductivities of doped modified natural rubber/PEO based electrolytes have higher values than conventional PEO based electrolytes at ambient temperature. In terms of the molecular structure of the polymer, ENR-25 and ENR-50 have an active oxygen in the epoxy group attached to their main chain. It is assumed that the ENR oxygen atom takes a role similar to the ether group in the PEO polymer structure and that Li cation solvation in ENR occurs as a result of coordination with the oxygen of the polar epoxy group in ENR.

ENR-50 would be expected to impose excessive coordination on the lithium cation thus repressing mobility. It seems also that this chemical modification of natural rubber enables it to be compatible and blend with PEO although thermal analysis results, presented in section 3.2, may initially seem to indicate otherwise. The addition of PEO into the modified ENR facilitates sample handling by decreasing the stickiness of the gel electrolyte, particularly when plasticizers are used.

When only the masticated rubbers and the lithium salt solution are mixed with ethylene carbonate (EC) and propylene carbonate (PC) to form a polymer electrolyte, the resultant cast films were slightly sticky and difficult to peel off from the substrate. Unusually the films bonded strongly to the Teflon substrate used in the casting stage of preparation. However, by the addition of a little PEO, the films could be peeled off easily. The details of thermal 
history of these films will be discussed in a later part of this section. This strong adhesive property may be significant in promoting efficient contact with the electrodes in electrochemical cell systems. Cell cycling tests [S. Rowlands and R. Idris, unpublished results] show reproducible behaviour. This indicates that the epoxy groups do not degrade under repeated recycling, thus giving support to the potential applicability of these materials in practical devices.

The conductivity value of the plasticized ENR-25/PEO and ENR-50/PEO systems containing lithium triflate are shown in figure 4.

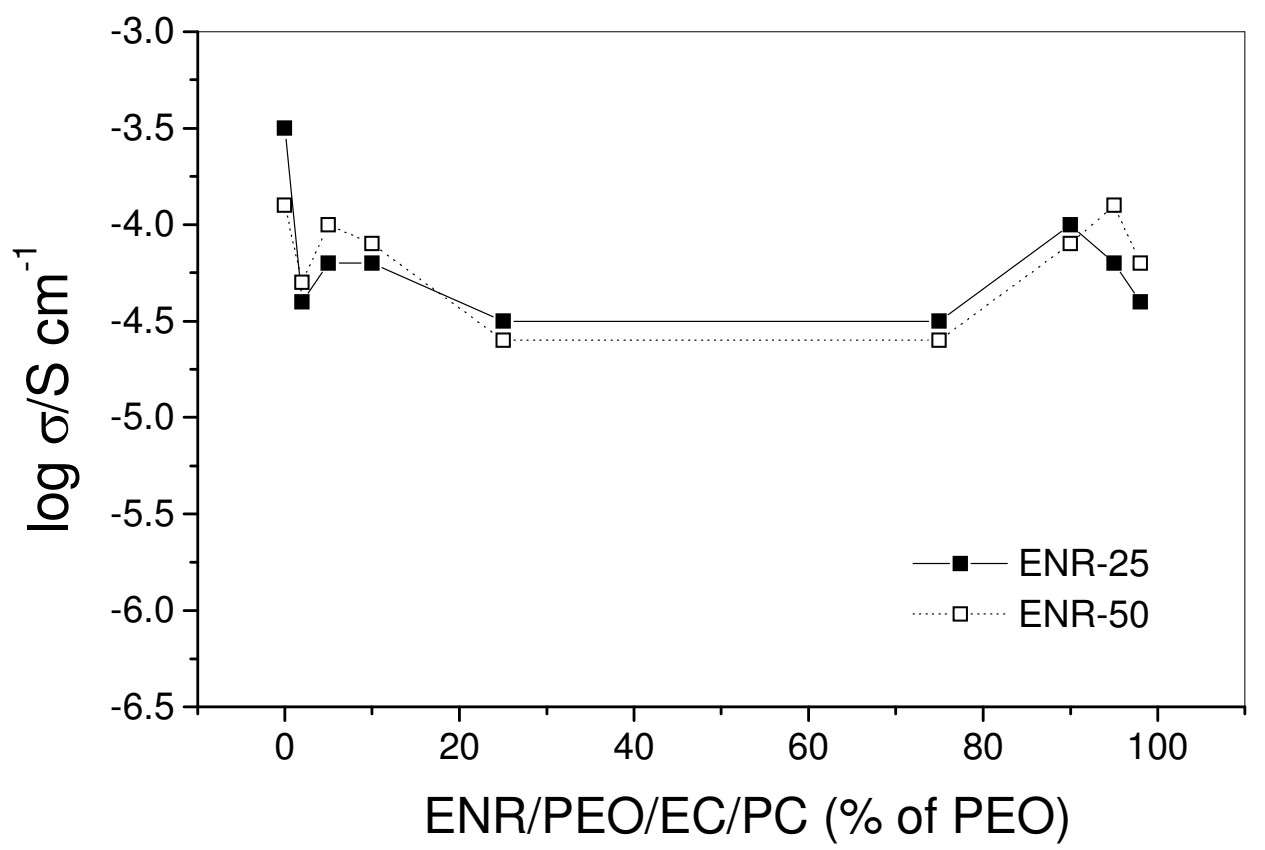

Figure 4 Conductivity as a function of PEO concentration of ENR/PEO/EC:PC/LiCF $\mathrm{SO}_{3}$ electrolytes at room temperature. The compositions are as defined in Section 2.1.

It was observed that the modified natural rubber/PEO based films have the ability to take up a high loading of polar low molecular weight organic plasticiser such as EC and PC. These polymer electrolyte films with ionic conductivities in the order $10^{-4} \mathrm{~S} \mathrm{~cm}^{-1}$ still retain their rubbery characteristics in spite of the presence of a large amount of absorbed electrolyte solution and the crystalline PEO.

These findings were compared with the work of Matsumoto et al [18] who studied synthetic elastomeric host matrices of poly(acrylonitrile-cobutadiene) and poly(styrene-co-butadiene) rubbers [19]. It was reported that an ionic conductivity of the order of $10^{-3} \mathrm{~S} \mathrm{~cm}^{-1}$ was obtained by swelling a polymer electrolyte system with electrolyte solvent. In this present, work a different material and approach has been used but the improvement in conductivity with addition of plasticiser mimics the above systems. It is suggested that the polarity of the both materials is one of the key factors to attain high ionic conductivity. It was reported that only polymers possessing high dipole moments are suitable candidates. Many of the recent studies on gel electrolytes have also reported employing polar matrices such as diacrylates, 
acrylonitrile-methyl methacrylate-styrene terpolymer [3,5]. Taking this into consideration, modified natural rubbers have fulfilled the above criteria in making a polymer electrolyte for potential use in lithium batteries.

\subsection{Differential Scanning Calorimetry}

Thermal analysis can reveal the presence of single or multiple glass transitions, thus indicating the number of amorphous phases present. For this reason, it is desirable to investigate the thermal properties prior to study. Addition of salt and plasticizer into the polymer electrolyte system ENR/PEO may cause changes in glass transition temperature. For this work, the phase behaviour of $\mathrm{ENR} / \mathrm{PEO} / \mathrm{LiCF}_{3} \mathrm{SO}_{3}$ electrolytes was investigated using differential scanning calorimetry, (DSC). Films made from modified natural rubbers/PEO$\mathrm{LiCF}_{3} \mathrm{SO}_{3}$ solutions appeared homogenous at room temperature. The glass transition, $\mathrm{T}_{\mathrm{g}}$, and melting temperatures, $\mathrm{T}_{\mathrm{m}}$, of the electrolytes based on $\mathrm{ENR} / \mathrm{PEO} / \mathrm{LiCF}_{3} \mathrm{SO}_{3}$ are shown in figures 5 and 6. It can be seen that Fox type behaviour [20-22] in which the inverse Tg would be a weighted fraction of the inverse glass transition temperature of the components, is not found. Because of the additional presence of salt, however, it is not possible to conclude that ENR and PEO are immiscible in the ratios used in these experiments. The ENR-25/PEO and ENR-50/PEO types of modified natural rubbers doped with lithium triflate in this study exhibited a single $\mathrm{T}_{\mathrm{g}}$ in the DSC experiments. For example, the $\mathrm{T}_{\mathrm{g}}$ of ENR-25, is $-43{ }^{\circ} \mathrm{C}$. This suggests that there is no microphase separation in this system, although it is recognised that the glass transition in PEO systems can be very difficult to identify.

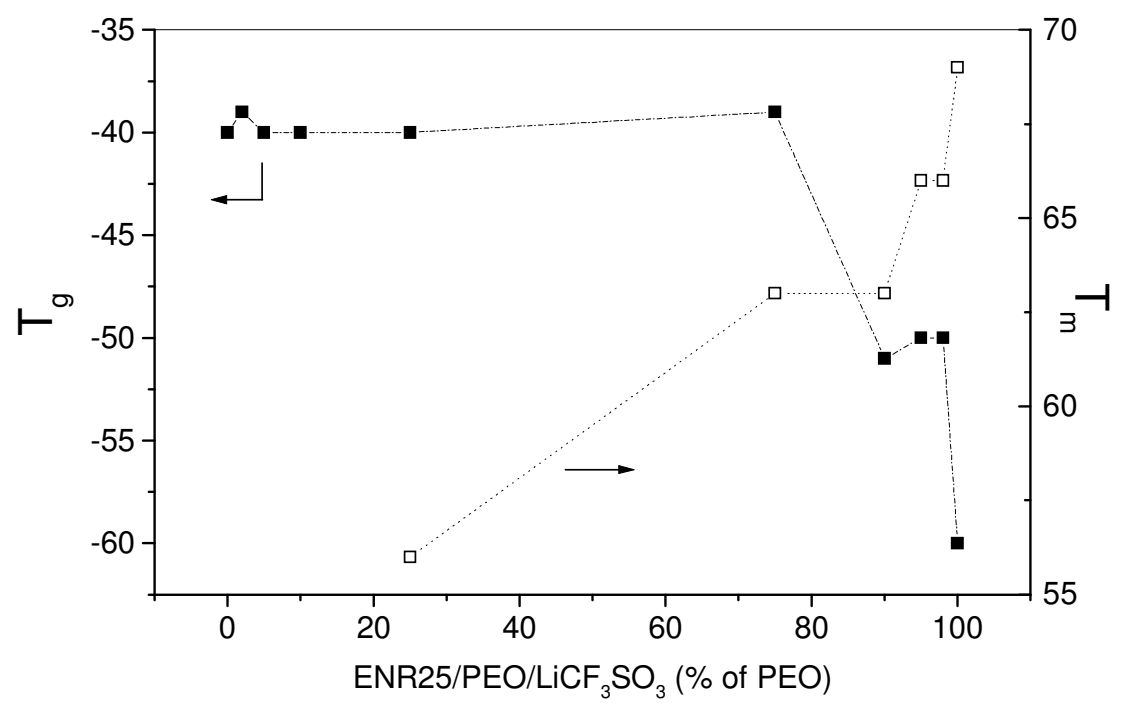

Figure 5 Results from DSC studies for polymer electrolytes based on ENR-25/PEO blends.

$\mathrm{T}_{\mathrm{g}}$ is found, in general to increase with increasing salt concentration. This indicates that a complex has formed between the rubber polymer and the lithium salt. The ionic mobility is closely related to the relaxation modes of the polymer host. This can be observed through the increase in $\mathrm{T}_{\mathrm{g}}$ of polymer systems as the salt concentration is increased. However, a lowering of $\mathrm{T}_{\mathrm{g}}$ values is observed as a result of incorporating plasticizers or solvents into the 
modified natural rubber matrices. It is suggested that the compatibility of the rubber and the solvent determines the optimised uptake of electrolyte species in the composition.

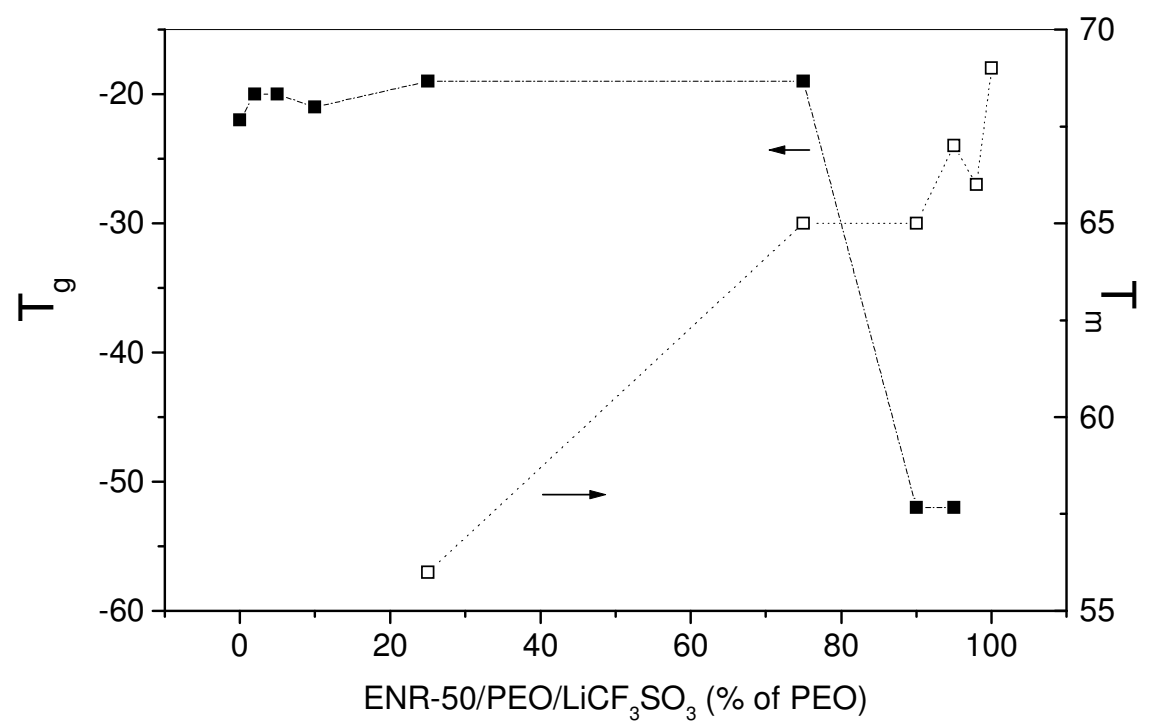

Figure 6 Results from DSC studies for polymer electrolytes based on ENR-50/PEO blends.

\section{Conclusion}

Modified natural rubber/PEO based electrolytes incorporating lithium triflate salt are potential polymer electrolytes. In addition, mixtures of ethylene carbonate (EC) and propylene carbonate (PC) enhance their ionic conductivities at room temperature.

The majority of the salt-doped polymer electrolyte systems have ionic conductivities about $10^{-5} \mathrm{~S} \mathrm{~cm}^{-1}$ at room temperature, irrespective of salt concentration. Similarly, it was found that plasticizing modified natural/PEO rubbers with $\mathrm{EC} / \mathrm{PC} / \mathrm{LiCF}_{3} \mathrm{SO}_{3}$ salt solution significantly increased their ionic conductivity. Ionic conductivities were in the range $10^{-4} \mathrm{~S}$ $\mathrm{cm}^{-1}$ at room temperature. The DSC traces of the salt-doped polymer electrolytes displayed a single transition glass $\left(\mathrm{T}_{\mathrm{g}}\right)$ temperature when increasing amount of PEO concentration was introduced into the polymer matrix.

\section{Acknowledgements}

The authors would like to thank SIRIM BHD; Malaysia for sponsoring RI and the Tun Abdul Razak Laboratory for supplying the modified natural rubbers.

\section{References}

[1] D-W. Kim, J. Power Sources 87 (2000) 78.

[2] M. Nashiura, M. Kono, N. Namegaya and Y. Matsuda, Electrochemical and Solid-State Letters 1 (1998) 246.

[3] R.A.M. Hikmat, M.P.J. Peeters, J. Lub and W. Nijssen, J. Electrochem. Soc. 146 (1999) 
2397.

[4] Y.K. Yavaroy, H.P Wang.and S. L Wunder, Solid State Ionics 118 (1999) 301.

[5] D-W. Kim, B-K. Oh and Y-M Choi, Solid State Ionics 23 (1999) 243.

[6] H.S Choe, B.G. Carroll, D.M. Pasquariello and K.M. Abraham, Chem. Mater. 9 (1997) 369.

[7] F. Croce, S. D. Brown, S. G. Greebaum, S. M Slane and M. Solomon, Chem. Mater. 5 (1995) 1.

[8] H. Tsutsumi, A. Matsuo, K. Onimura and T. Oishi, Electrochem. and Solid State Lett. 1 (1998) 244.

[9] L.R.A.K. Bandara, M.A.K.L. Dissanayake and B.E. Mellander, Electrochim. Acta 43 (1998) 1447.

[10] D. Ostrovskii, L. M. Torell, G.B Appetecchi. and B. Scrosati, Solid State Ionics 106 (1998)19.

[11] G.B. Appetecchi, F. Croce and B. Scrosati, J. Power Sources 66 (1997) 77.

[12] H-Y. Sung, Y-Y. Wang, and C-C. Wan, J. Electrochem. Soc, 145 (1998) 1207.

[13] G. Venugopal, V. R Reicher and J. Zhang, US Patent 5,549, 987. 27 (1996).

[14] A.M. Voice, J.P Southall, V. Rogers, K.H. Mattews, G.R. Davies, J.E. McIntyre and I.M. Ward, Polymer 35 (1994) 3363.

[15] F. Croce, G.B. Appetecchi, S. Slane, M. Salomon, M. Tavarez, S. Arumugam, Y. Wang and S.G. Greenbaum, Solid State I.onics 86/88 (1996) 307.

[16] M. Kono, E. Hayashi and M. Watanabe, J. Electrochem. Soc. 146 (1999) 1626.

[17] C. Kim, G. Lee, K. Liou, K. S. Ryu, S.G. Kang and S. H Chang, Solid State Ionics 123 (1999) 251.

[18] B. Scrosati, F. Croce and L. Persi, J. Electrochem. Soc.147 (2000) 1718.

[19] M. Matsumoto Polymer 37 (1996) 625.

[20] T.G.Fox, Bull. Amer. Phys. Soc, 1 (1956) 123.

[21] T.G.Fox and P.J.Flory, J. Polym. Sci. 14 (1954) 314.

[22] P.R.Couchman, Macromolecules 11 (1978) 1156. 